\title{
An Epidemiology of Sport Injury Rates Among Campus Recreation Sport Programs
}

\author{
Skye Gerald Arthur-Banning ${ }^{1}$,, David Jameyson ${ }^{2}$, Katrina Black ${ }^{1}$, Peter Mkumbo ${ }^{1}$ \\ ${ }^{1}$ Department of Parks, Recreation and Tourism Management, Clemson University, Clemson, USA \\ ${ }^{2}$ Athletics Department, Ashland University, Ashland, USA

\section{Email address:} \\ sarthur@clemson.edu (S. G. Arthur-Banning), djameyso@ashland.edu (D. Jameyson), klblack@clemson.edu (K. Black), \\ pmkumbo@clemson.edu (P. Mkumbo) \\ ${ }^{*}$ Corresponding author
}

\section{To cite this article:}

Skye Gerald Arthur-Banning, David Jameyson, Katrina Black, Peter Mkumbo. An Epidemiology of Sport Injury Rates Among Campus Recreation Sport Programs. Rehabilitation Science. Vol. 3, No. 2, 2018, pp. 38-42. doi: 10.11648/j.rs.20180302.13

Received: June 6, 2018; Accepted: July 26, 2018; Published: August 23, 2018

\begin{abstract}
Injuries are one of the common risks associated with physical activity. At the collegiate level of sports participation, NCAA sports programs are required to provide injury treatment and prevention options for their athletes. However, for participants competing in club and intramural sports, no universal requirements for injury prevention and treatment exist. This study assessed the risk of injury during club and intramural sports among college-aged students compared to participants in NCAA sports. Overall, club sport participants were found to have a significantly higher rate of injury compared to previously documented injury rates in NCAA participants, while, both NCAA and club sports participants were found to be more at risk than intramural participants. Specific sport injury rates were documented for nine club sports and compared with NCAA injury data. These injury rates suggest a need for improved health care and preventative treatment options for club sport athletes, especially in club sport rugby.
\end{abstract}

Keywords: Intramural Sports, Club Sports, NCAA, Injury Rates, Intensity

\section{Introduction}

The sports medicine industry is a multi-billion dollar industry that encompasses the medical treatment and care of injured athletes [1-3]. The industry has grown rapidly in the past few decades due to the increasing number of people playing competitive sports and, as a result, a larger number of injuries that occur while playing. In the United States, roughly 7.5 million students participate in competitive sports at the high school level alone, which also results in about 1.4 million injuries annually ranging from both lower and upper extremity injuries, concussions, and other common orthopedic injuries [3]. The estimated cost for the direct and indirect treatment of these injuries is over $\$ 6.7$ billion a year [2]. The high number of participants in competitive sports and the cost involved has encouraged many institutions to employ medical staff such as a physician, physical therapist, or certified athletic trainer on a full time basis to improve the quality of care for participants. This not only decreases the number of injuries, but also provides participants a means for treatment after an injury occurs, and in most cases, gives them a more affordable option for treatment $[4,5]$.

The National Athletic Trainers Association's (NATA) definition of "appropriate medical coverage" goes well beyond the need for an emergency action plan. Other duties recommended include daily interaction with student athletes to assess risk of injury, injury prevention, evaluation and immediate care of injury, rehabilitation, psychosocial interaction and nutritional aspects of sports to name a few [5]. To represent the risk of injury for different populations and activities, injury rates are often collected and analyzed through injury surveillance systems, and can lead to more informed injury prevention initiatives.

At the collegiate club sport and intramural levels of competition, very little is known about national injury rates. This may be because the National Intramural-Recreational Sports Association (NIRSA) does not currently have an injury reporting system. Institutions are also not required to 
be a part of NIRSA to support intramural and club sport programs. Each institution likely has their own injury rates, but the trends for the entire population are largely unknown.

In any type of sport and recreation activity, competitive or non-competitive, one of the most commonly used predictors of injury risk is the training demand. Injuries will be more or less likely to occur depending on the training demands required for that activity, especially with competitive sport. The specific activity will also have an influence on the potential risk involved in physical activity. Recently, advanced technology, more advanced play, and more participants in high-risk activities have resulted in more injuries in team sports such as football and hockey, as well as individual sports such as snowmobiling or driving an allterrain vehicle (ATV) [6]. This has also been shown to relate to injuries seen in physical education students, with the most common injuries resulting from participation in higher risk sports such as football, soccer, basketball, and volleyball [7].

\section{Rationale}

Participating in sports can be very beneficial mentally, physically, and socially $[8,9]$. However, sport injuries can be a barrier for participants to realize the benefits that come along with participation. The purpose of this study is to determine how injury rates differ between club, intramural, and NCAA sport levels of competition in a collegiate setting and to make appropriate recommendations to decrease these rates and ultimately provide better outcomes for participants at all levels of sport. To assess varying risks of injury within these populations and activities, a research project that involved intramural sports at a university located in the southeastern United States was designed to investigate the differences in the type of reported injuries between NCAA and club sports. The findings are eventually expected to enhance any future decisions with regard to medical coverage in sports and any policies that relate to sport injury rates.

\section{Methods}

This study examined archived injury reports collected over a two-year period for all club sports. Injury information was collected and examined at a University in the southeast where bad weather rarely plays an issue in injury rates unless it is the extreme heat. Certified Athletic Trainer SOAP (Subjective, Objective, Assessment, Plan) notes were compiled and examined for club sport injury trends and frequencies. Intramural injury information was collected by using campus recreation incident reports to gain a general idea of the risks involved during intramural sport. To be included in this study, injuries must have occurred during participation in club or intramural activity, must have required medical attention, must have been reported to a certified athletic trainer, and must have limited participation for at least one day following injury. Intramural injuries were included if they were reported to a campus recreation employee, required some form of medical treatment outside of general first aid, limited the athlete's participation for at least one game, and were documented using a campus recreation injury or incident form.

All injury reports were completed by a Certified Athletic Trainer or another associated health care professional using the Sportsware or Point and Click injury documentation software, or by using an incident report form. Injury reports and information are different for each person documenting an injury, however the standard injury report typically includes (a) type of injury (e.-g., strain, sprain, fracture, catastrophic injury), (b) body part injured, (c) mechanism of injury (noncontact, player to player contact, etc.), and (d) the activity and location when the injury occurred. Injury and incident reports that were included in this study are sporting activity and injury rates. Intramural injuries were documented using campus recreation incident reports and were not typically completed by a health care professional. These incident reports were only used to compare frequencies, and were not analyzed for accuracy or specific injuries since they were not completed by someone with injury documentation experience or training. Data was then compared between sports and levels of competition, as well as with the previous data on NCAA injury rates.

The number of sport interactions was then compared to the total number of injuries and used to describe the frequency of injury. This information was collected by examining previously documented club sport field reports and practice summaries. The total number of injuries was compared with the number of sport interactions. This resulted in a ratio for every sport with the number of injuries compared to the number of interactions such as: $x$ amount of injuries for every 1,000 games. Injury ratios for games and practices were then compared to previously established injury rates.

NCAA rates were used from a previous study that collected data over sixteen years for 15 varsity sports. Intramural sports injury reports were collected for 8 sports over at two year period of time from the same university using campus recreation reports. Only injury reports completed by a certified athletic trainer or team physician were included for club sport injuries. Injury reports were examined by a second health care professional (either an athletic trainer or team physician) before being included in the study to make sure the standards are met.

\section{Results}

Upon verification of injury rates and analysis, the following results are reported. Table 1 shows game competition injury rates and practice injury rates. Club sports injury rates of 18.3 were found to be significantly greater than both NCAA injury rates, $13.79(\mathrm{P}=0.00249)$ and intramural sports injuries $10.28(\mathrm{P}<.0001)$. The game injury rate for NCAA were also significantly greater than the intramural rate of injuries $(\mathrm{P}<0.0001)$. Practice injury rates were compared between NCAA of 3.9 and club sports of $3.8 / 1000$ injuries, however there is not a significant difference between the two levels of competition $(\mathrm{P}=0.704)$. 
The practice injury rates were calculated using the total number of practice exposures and injuries by sport. Over 16,000 total exposures were documented for 9 club sports. In general, fewer injuries occurred during practices than in games, similar to what was found in the NCAA injury sample. Men's soccer decreased from a game injury rate of 13.18 to a practice injury rate of 8.03 ; however the practice injury rate of 8.03 was still almost double the injury rate found in NCAA men's soccer of 4.3, where medical staff is present. Men's club rugby still remains the highest injury rate of all sports at 7.97 injuries per 1,000 exposures.

Table 1. Injury rates NCAA and club sport game and practice injury rates per 1,000 athletic exposures.

\begin{tabular}{lllll}
\hline \multirow{2}{*}{ Sports } & \multicolumn{2}{l}{ Game Injury Rates } & \multicolumn{2}{l}{ Practice Injury Rates } \\
\cline { 2 - 5 } & NCAA & Club Sport & NCAA & Club Sport \\
\hline Men's Ultimate & & 1.34 & & 0.44 \\
M. Rugby & & 36.42 & & 7.97 \\
M. Basketball & 9.9 & & 4.3 & \\
M. Soccer & 18.8 & 13.18 & 4.3 & 8.03 \\
M. Wrestling & 26.4 & & 5.7 & \\
M. Ice Hockey & 16.3 & & 2.0 & \\
Softball & 4.3 & & 2.7 & \\
W. Volleyball & 4.6 & & 4.1 & \\
W. Lacrosse & 7.2 & & 3.3 & 1.15 \\
W. Basketball & 7.7 & & 4.0 & \\
W. Volleyball & 4.6 & & 4.1 & \\
W. Rugby & & 52.63 & & 4.30 \\
W. Soccer & 16.4 & 11.06 & 5.2 & 2.99 \\
W. Gymnastics & 15.2 & & 6.1 & \\
W. Field Hockey & 7.9 & & & \\
W. Ice Hockey & 12.6 & & 2.5 & \\
\hline
\end{tabular}

According to the injury report collected over the two-year period from campus recreation, intramural sports reported 539 injuries, which occurred during 52,434 exposures, equaling an injury rate of 10.28 injuries per 1,000 exposures. In Table 2, when comparing injury rates among the different club sports, rugby, both women and men teams were at the highest risk for injury exposures 52.63 and 36.42, respectively, however, please note the sample size for women rugby was smaller than that of the men rugby team. In men's ultimate Frisbee showed the lowest injury rate at only 1.34, while women's ultimate Frisbee had an injury rate of 9.15.

Table 2. Z-score Campus Rec Injuries.

\begin{tabular}{llll}
\hline & Pooled Proportion & Z-Score & P-Value \\
\hline NCAA vs Club Sport Games & 0.13755253 & -3.0235 & $0.00249 *$ \\
NCAA vs Club Sport Practices & 0.003983411 & 0.3798 & 0.704 \\
NCAA vs Intramural Games & 0.013755253 & 6.867 & $<.0001^{*}$ \\
Club Sport vs Intramural Games & 0.011117942 & 5.663 & $<.0001^{*}$ \\
\hline
\end{tabular}

The $\mathrm{Z}$ score when comparing NCAA and club sport games was -3.0235 with p-value (0.00249), which represents the probability of observing a sample statistic as extreme as the test statistic. As it could be notated by the p-value (table 2 above), there is a significant difference between the NCAA and club sport injury rate. The same formula is used for a one-tailed test to determine which sample has a greater risk of injury. The z-score (-3.0235) remains the same, however the p-value changes to.00126, which is still less than the level of significance. The $\mathrm{Z}$ score reflects a negative score, this indicates further that club sports shows a significant rate of injury during games than NCAA competition. Intramural injury rates are significantly different then the NCAA and club sports rate. When compared with NCAA and club sports injury rates, intramural sports injury rates were significantly different than both NCAA and club sport injury rates. Two separate z-test were run with NCAA and club sports both being used as P1 and intramural sports as P2 in each case. For the NCAA test statistic was a $\mathrm{z}$-score of 6.867 , while the club sport comparison resulted in a z-score of 5.663. Both of these test statistics confirmed proportion one was significantly greater. The P-value for both tests were less than 0.001 , which is less than the level of significance.

Practice injury rates were also compared between the two groups; however the null hypothesis was not rejected. The pvalue $(0.704)$ is greater than the level of significance, so with our samples, we cannot conclude that there is a difference in the rates of injury during practices. Intramural injury rates are significantly different than the NCAA and club sports rate. (Table 2).

\section{Discussion}

Injury rates and impact on sport participation in University sport play is an important element to an enjoyable sport experience for athletes and casual participants [10]. Overall, one could argue that injury rates may be partially impacted by the intensity of the activity, the level of competition, and the participant ability [11]. In this study, intramural sports were found to have the lowest level of competition and intensity, and have the lowest rate of injury during games. This is partly due to the reason why individuals participate in intramural sports, which is heavily influenced by recreation or leisure rather than a serious, intense competition that club or NCAA sports imply. On the other hand, NCAA athletes are assumed to show the highest level of competition and intensity and so one would believe the injury rates for this population whether in preparatory practices or in actual games, would be the highest in comparison to sport clubs and intramural sports. Surprisingly, while it is true that NCAA athletes have a higher risk of injury than intramural participants, this study found that injury rates among NCAA athletes were unexpectedly lower than club sport participants during game competitions. Thus, club sports participants were found to have the highest risk of injury during games in this study. This would suggest that even though participants compete at the intermediate level of competition, club sport athletes may have less ability, conditioning, or are not well prepared for the proper intensity that is experienced in club sport games. It also suggests that participants in club sports might be in transition from making sports a significant part of the persona or develop themselves into a different nonathletic individual identity.

Intensity of competition is relatively lower in practices as compared to the level of intensity in games for both NCAA and club sports, leading to lower injury rates (Table 1). This 
supports the argument of how athlete ability and level of competition affect injury rate and implies that injury rates are related to level of competition in which injuries are lower in practice exposures and higher in game exposures [12]. There may be resistance when practicing with playmates and how forceful the intensity is within the scenario compared to game time and when the goal is simply to win. However, there is not enough evidence statistically to support the significance of differences between NCAA and Club Sports during practices. On one hand this could be argued that the medical coverage for an NCAA athlete has no significant difference in the risk of injury rates during practices when compared to a club sport that doesn't have medical coverage as the injury rates were not statistically significantly different between NCAA and Club Sports during practices. On the other hand, one could argue that medical coverages for Club Sports should be nearly or the same as those of NCAA athletes if injury rates are similar.

As mentioned earlier, engagement in sport activities is good for many reasons, some being improving the mental and physical fitness of participants, however, injuries associated with involvement in sport could severely affect any of the expected benefits and might as well have a negative impact like poor academic performance for students through missed class times due to injuries or concussion symptoms causing loss of focus and change of study habits. Appropriate medical coverage means that certified individuals would provide more than just basic emergency care. This type of care encompasses a number of daily activities to ensure the student recovers and is back to daily functional living as soon as possible. These activities include but are not limited to risk management, injury prevention, reconditioning of athletic injuries, and pre-participation evaluations [5]. Therefore, having an athletic trainer in place, specifically in women's rugby, women's soccer and men's soccer club sports, would be beneficial.

Furthermore, injury prevention needs to be considered as a major component to competition levels involving games and practices, particularly at the sport club level [13]. Some injuries are preventable and should be prevented by incorporating appropriate training and safety measures [14]. Chalmers (2002) reports that injuries do not have to be a part of the sporting activity as most people will attest that if you are playing some type of sport, participants stand a chance at getting injured. Step one is to increase recognition of particular sport related injuries and then provide a strong preventative approach to correcting the issue as a means of reducing injury rates [15].

\section{Conclusion and Implications}

From the results, it could be concluded that, an NCAA athlete who is well-trained is less likely to be injured in a game competition compared to a Club Sport athlete possibly due to their level of sport skills, the intensity of the sport and less attention to conditioning and prevention techniques performed in training. It is also important to recognize that based on this study, an athlete regardless of their participation in NCAA or Club Sport is less likely to be injured in practices than in game competitions due to the fact that intensity of competition is lower in practices than in game competitions. Among all three categories (NCAA, Club Sports and intramural), injury rates are lowest in intramural game competitions partly due to the fact that involvement in intramural games is largely recreational in nature and thus the level of intensity is lowest in comparison to NCAA and Club Sport game competition exposures. This applies to those who are looking to play a sport that requires minimal injuries but will allow a team experience.

Club rugby, among all sports, demonstrated the highest likelihood of risk and exposure to injury partly due to full physical contact among players. Therefore, it is highly suggested that preventative equipment be worn at all times, which consists of head gear, mouth guard, and proper technique be taught through training as well as preventative taping, strength conditioning and risk assessments performed on facilities by certified trainers, even at the club sport level. Participant will be responsible for signing off on receiving this training in order to play all categorical sporting activities but ultimately, having an athletic training on site for Club sport game competitions, particularly in rugby and soccer potentially reduce serious injuries that would limit future participation.

Limitations to this study consist of the non-overlapping of different sporting activities; among the NCAA and Club sports there were only five sports of which a strong comparison could be made. This limitation posed a barrier in providing more concrete comparisons for the competition levels and categorical sports. Further research should be done in areas where injury rates are found in similar context so that a better relationship of injury rates across multiple sports can be seen. However, the current study information can be beneficial and used when deciding which sport to play with minimal risk for college students while it can also provide information for program managers to allocate appropriate certified medical staff such as athletic trainers to specific sporting events.

This study implies that athletic trainers are needed at every function of sporting events, particularly Club sport games. More importantly, their attendance is needed in order to be able to properly prepare, train and assess players in each phase of the sport environment. The NCAA has recognized the need to keep their athletes safe and it would be hoped that campus recreation staff and programs also recognize that as sport continues to develop and grow, the risks of injury for club sport and intramural athletes also increase and having trained medical staff on site to assist in campus recreation programs can help keep athletes safer. 


\section{References}

[9] Recours, R. A., Souville, M. \& Griffet, J (2017). Expressed Motives for Informal and Club/Association-based Sports Participation, Journal of Leisure Research, 36:1, 1-22.

[1] Houston M, Peck K, Cameron K, et al. (2017). The incidence of ankle injuries in intramural and club sports at the united states military academy; British Journal of Sports Medicine, 51:A1.

[2] Conn, J. M., Annest, J. L., \& Gilchrist, J. (2003). Sports and recreation related injury episodes in the US population $1997-$ 99. Injury Prevention; 9(2): 117-122.

[3] McGuine, T. A. (2010). Athletic training in the secondary school setting: toward a national agenda. Human Kinetics; 15(6): 1-3.

[4] National Athletic Trainers' Association. (2002). Position Statement: Emergency Planning in Athletics. Journal of Athletic Training; 37(1): 99-104.

[5] National Athletic Trainers' Association. (2007). Recommendations and guidelines for appropriate medical coverage of intercollegiate athletics. National Athletic Trainers 'Association; 1-18.

[6] Tator, C. H. (2011). Risk of catastrophic injury in sports and recreation. Sport in Society: Cultures, Commerce, Media, Politics; 14(9): 1291-1299.

[7] Ray, M. K. J., \& Kohandel, M. (2010). Epidemiology of some sport injuries among physical education college students. Injury Prevention; 16: A1-A289.

[8] McElveen, M., North Jr., T., Rossow, A., \& Cattell M. (2014). Injury Rates in Intramural Sports. Recreational Sports Journal; 38: 98-103.

[10] Moseid CH, Myklebust G, Fagerland MW, Clarsen B, Bahr R. The prevalence and severity of health problems in youth elite sports: A 6-month prospective cohort study of 320 athletes. Scandanavian Journal of Medicine and Science in Sports. 2018;28:1412-1423.

[11] Luiggi, M., Rindler, V., \& Griffet, J (2018). From which level of competition in clubs are adolescents at greater risk of injury compared with outside-of-clubs athletes? A school-based study, The Physician and Sportsmedicine, 46:1, 66-72.

[12] Hootman, J. M., Dick, R., \& Agel, J. (2007). Epidemiology of collegiate injuries for 15 sports: summary and recommendations for injury prevention initiatives. Journal of Athletic Training; 42(2): 311-319.

[13] Samson, C. O., Straw, C. M., Henry, G. M., \& Brown, C. N. (2017). History of major lower extremity injury associated with subsequent injury in collegiate club sport athletes. Journal of Athletic Training, 52(6), 1.

[14] National Athletic Trainers' Association. (2002). Position Statement: Exertional Heat Illnesses. Journal of Athletic Training; 37(3): 329-343.

[15] Chalmers, D. J. Injury prevention in sport: not yet part of the game? Injury Prevention. 2002; 8:iv22-iv25 doi 10.1136/ip.8.suppl_4.iv22. 